\title{
Effects of Electron-Withdrawing Groups at C-2 Position of 1,6-Anhydro-Sugars on Their Polymerizabilities
}

\author{
Ken-Ichi Kanno, Yuichi Kobayashi, and Kenichi HatanaKa* \\ Department of Biomolecular Engineering, Tokyo Institute of Technology, \\ 4259 Nagatsuta-cho, Midori-ku, Yokohama 227, Japan.
}

(Received June 17, 1994)

\begin{abstract}
Anhydro- $\beta$-D-mannopyranose derivatives having electron-withdrawing groups at $\mathrm{C}$-2, i.e., 1,6-anhydro-3,4-di- $O$-benzyl-2- $O$-methanesulfonyl- $\beta$-D-mannopyranose (5), 1,6-anhydro-2- $O$-benzoyl-3,4-di- $O$-benzyl- $\beta$-D-mannopyranose (6), and 1,6-anhydro-3,4-di- $O$-benzyl- $\beta$ D-arabino-hexopyranos-2-ulose (7) were synthesized, and polymerized under cationic conditions. The polymerization of 5 gave stereoregular polysaccharide with high molecular weight. On the other hand, the polymerization of 6 yielded lower molecular weight polysaccharide, and 7 showed no polymerizability under various conditions. Differences in the reactivity among 1,6-anhydro sugar derivatives having various electron-withdrawing groups at $\mathrm{C}-2$ are discussed.

KEY WORDS Ring-Opening Polymerization / 1,6-Anhydro- $\beta$-D-Mannopyranose Derivatives / Effects of Electron-Withdrawing Groups / Polymerizabilities /
\end{abstract}

Since polysaccharides play important roles physiologically, pharmaceutical applications of polysaccharides have been attempted. Synthetic technology of polysaccharides has stimulated bioscience, and such technology is utilized in the fields of food chemistry, medical supplies, and other industries. Some methodologies have been reported about the preparation of polysaccharides such as stepwise ${ }^{1}$ or blockwise synthesis, ${ }^{2}$ polycondensation, ${ }^{3}$ enzymatic synthesis, ${ }^{4,5}$ and ring-opening polymerization of anhydro sugar derivatives. ${ }^{6,7}$ Ring-opening polymerization is well suited for the synthesis of high moleculer weight glycans. The established relative polymerizabilities of benzylated 1,6-anhydro- $\beta$-D-hexopyranoses are in the order: mannose $>$ glucose $>$ galactose. Polymerizabilities of 1,6-anhydrosugar derivatives and stereoregularities of the obtained polysaccharides are much dependent on the protective groups. Especially, the effect of the substituent at C-2 on the polymerizability is of interest because of its electrical and steric influences on the polymeric active end.

In recent years, Kobayashi et al. reported the polymerization of 1,6 -anhydro- $\beta$-D-galactopyranose having benzoyloxy group at C-2. The polymerization proceeds with double inversion at $\mathrm{C}-1$ by the formation of acyloxonium ion, ${ }^{8}$ leading to 1,2 -trans-glycoside, that is, $(1 \rightarrow 6)-\beta$ D-galactopyranan derivative. ${ }^{9}$ Polymerizations of benzylated 1,6-anhydro-sugar monomers proceed usually with single inversion at C-1 leading to $(1 \rightarrow 6)-\alpha$-D-hexopyranans. ${ }^{10,11}$

In this study, the synthesis of 3 kinds of 1,6 -anhydro- $\beta$-D-mannopyranose derivatives having electron-withdrawing groups at $\mathrm{C}$ 2 , i.e., 1,6-anhydro-3,4-di-O-benzyl-2-O-methanesulfonyl- $\beta$-D-mannopyranose (5), 1,6-anhydro-2-O-benzoyl-3,4-di- $O$-benzyl- $\beta$ D-mannopyranose (6), and 1,6-anhydro-3,4-di$O$-benzyl- $\beta$-D-arabino-hexopyranos-2-ulose 7 .

\footnotetext{
* To whom correspondence should be addressed.
} 
The effects of electron-withdrawing substituents at C-2 of 1,6-anhydro-sugars on polymerizabilities were investigated.

\section{EXPERIMENTAL}

\section{General Methods}

270-MHz ${ }^{1} \mathrm{H}-\mathrm{NMR}$ spectra were measured for solutions in $\mathrm{CDCl}_{3}$ with tetramethylsilane as internal reference by a JEOL EX-270 spectrometer. Optical rotations were measured in $\mathrm{CHCl}_{3}$ by a digital polarimeter. Gelpermiation chromatography was carried out with a Shimadzu LC-9A using GPC-802, 803, and 804 column.

\section{1,6-Anhydro-2,3-O-(S)-benzylidene- $\beta$-D- mannopyranose (2)}

1,6-Anhydro- $\beta$-D-mannopyranose $(1 ; 5.0 \mathrm{~g}$, $30.9 \mathrm{mmol}$ ), prepared from D-mannopyranose by the method of Fraser-Reid, ${ }^{12}$ was dissolved in dried dimethylformamide $(20 \mathrm{ml})$. After adding $\alpha, \alpha^{\prime}$-dimethoxytoluene $(30 \mathrm{ml}$, $209 \mathrm{mmol})$ and $p$-toluenesulfonic acid $(0.6 \mathrm{~g}$, $3.15 \mathrm{mmol}$ ), the reaction mixture was stirred for $1 \mathrm{~h}$ at $50^{\circ} \mathrm{C}$ under unhydrous conditions. The residue was taken up by chloroform $(200 \mathrm{ml})$, neutralized, and successively washed by water. 2 was crystallized from ethanol. $(5.02 \mathrm{~g}, 65.2 \%),[\alpha]_{\mathrm{D}}^{21}=-44.6^{\circ}, \delta_{\mathrm{H}}: 3.86(\mathrm{t}, 1 \mathrm{H}$, $\left.J_{5,6}=7.59, J_{6,6}=6.26, \mathrm{H} 6\right), 4.07\left(\mathrm{t}, 1 \mathrm{H}, J_{4,5}=\right.$ $1.32, \mathrm{H} 4), 4.09\left(\mathrm{t}, 1 \mathrm{H}, J_{2,3}=1.98, \mathrm{H} 2\right), 4.21(\mathrm{t}$, $1 \mathrm{H}, \mathrm{H} 3), 4.25\left(\mathrm{t}, 1 \mathrm{H}, J_{5,6^{\prime}}=0.99, \mathrm{H} 6^{\prime}\right), 4.60(\mathrm{~m}$, $1 \mathrm{H}, \mathrm{H} 5), 5.51$ (s, 1H, H-1), $5.77\left(\mathrm{~s}, 1 \mathrm{H}, \mathrm{H}_{\mathrm{CHPh}}\right)$, $7.41\left(\mathrm{q}, 4 \mathrm{H}, \mathrm{H}_{\mathrm{Ph}}\right), 7.65\left(\mathrm{~s}, 1 \mathrm{H}, \mathrm{H}_{\mathrm{Ph}}\right)$.

\section{1,6-Anhydro-4-O-benzyl-2,3-O-(S)-benzyli- dene- $\beta$-D-mannopyranose (3)}

A solution of 1,6-anhydro-2,3-O-(S)-benzylidene- $\beta$-D-mannopyranose $(2 ; 5.04 \mathrm{~g}, 20.2$ mmol) in dimethylformamide $(50 \mathrm{ml})$ was dropped into a suspension of sodium hydride $(1.93 \mathrm{~g}, 80.5 \mathrm{mmol})$ in dimethylformamide $(150 \mathrm{ml})$ spending $5 \mathrm{~h}$ at $20^{\circ} \mathrm{C}$. After stirring for 1 additional hour, benzyl chloride $(5.12 \mathrm{ml}$, $44.5 \mathrm{mmol})$ in dimethylformamide $(45 \mathrm{ml})$ was dropped onto the residue. The reaction mixture was stirred for $16 \mathrm{~h}$, and quenched by adding methanol. The residue was taken up by 1 liter of chloroform, washed by water and 3 was crystalized from the solution of ethanol. $(6.45 \mathrm{~g}, 93.9 \%),[\alpha]_{\mathrm{D}}^{21}=-41.8^{\circ}, \delta_{\mathrm{H}}: 3.78(\mathrm{~s}$, $1 \mathrm{H}, \mathrm{H}-4), 3.83\left(\mathrm{~d}, 1 \mathrm{H}, \mathrm{H}-6^{\prime}\right), 3.95(\mathrm{~d}, 1 \mathrm{H}$, $\left.J_{6,6}=7.26, \mathrm{H}-6\right), 4.26(\mathrm{~d}, 1 \mathrm{H}, \mathrm{H}-2), 4.28(\mathrm{~d}$, $\left.1 \mathrm{H}, J_{2,3}=6.93, \mathrm{H}-3\right), 4.66(\mathrm{~m}, 1 \mathrm{H}, \mathrm{H}-5), 4.67$, $4.75\left(\mathrm{~d}, 2 \mathrm{H}, J=12.2,-\mathrm{CH}_{2} \mathrm{Ph}\right), 5.52(\mathrm{~d}, 1 H$, $\left.J_{1,2}=2.97, \mathrm{H}-1\right), 5.76\left(\mathrm{~s}, 1 \mathrm{H}, \mathrm{O}_{2} \mathrm{CHPh}\right), 7.38$, 7.39 (s, 10H, Ph).

\section{1,6-Anhydro-3,4-di-O-benzyl- $\beta$-D-mannopy- ranose (4)}

1,6-Anhydro-4-O-benzyl-2,3-O-(S)-benzylidene- $\beta$-D-mannopyranose $(3 ; 6.45 \mathrm{~g}, \quad 19.0$ mmol) was dissolved in a suspension of litium aluminum hydride $(0.735 \mathrm{~g}, 19.4 \mathrm{mmol})$ in reaction the solvent (dichloromethane and diethylether $=50$ and $150 \mathrm{ml}$ ), in which aluminum chloride had been added and stirred for $30 \mathrm{~min}$ at $40^{\circ} \mathrm{C}$. The residue was cooled and the reaction was quenched by the addition of water. The residue was taken up by chloroform, washed by water, dried, evapolated, and chromatographed on silica-gel (hexane : ethyl acetate $=2: 3$ eluent). 4 was crystalized from syrupy state. $(3.96 \mathrm{~g}, 60.6 \%)$, $[\alpha]_{\mathrm{D}}^{21}=-58.3^{\circ}, \delta_{\mathrm{H}}: 2.04(\mathrm{~s}, \mathrm{OH}), 3.49(\mathrm{~s}, 1 \mathrm{H}$, $\mathrm{H}-4), 3.69\left(\mathrm{dd}, 1 \mathrm{H}, J_{5,6}=5.94, J_{6,6^{\prime}}=6.93\right.$, $\mathrm{H}-6), 3.73$ (q, 1H, H-2), 3.78 (m, 1H, $\mathrm{H}-3$ ), 4.07 (dd, $\left.1 \mathrm{H}, J_{5,6}=0.99, \mathrm{H}-6\right), 4.50$ 4.55 (m, 5H, H-5, - $\left.\mathrm{CH}_{2} \mathrm{Ph}\right), 5.35$ (s, 1H, H-1), 7.34 (10H, Ph).

\section{1,6-Anhydro-3,4-di-O-benzyl-2-O-methanesul-} fonyl- $\beta$-D-mannopyranose (5)

To a cooled $\left(0^{\circ} \mathrm{C}\right)$ solution of 1,6-anhydro3,4-di- $O$-benzyl- $\beta$-D-mannopyranose $(4 ; 2.0 \mathrm{~g}$, $5.85 \mathrm{mmol})$ in pyridine $(5 \mathrm{ml})$, methanesulfonyl chloride $(0.588 \mathrm{ml}, 7.60 \mathrm{~mol})$ was injected slowly, and stirred for $30 \mathrm{~min}$. The residue was taken up by chloroform, and washed by water. After chromatography by silica-gel (benzene: ethyl acetate $=1: 1), 5$ was purified by five times 
of recrystalization from 1-chlorobuthane solution. $(1.72 \mathrm{~g}, 78.2 \%),[\alpha]_{\mathrm{D}}^{22}=-5.6^{\circ}, \delta_{\mathrm{H}}$ : $3.04\left(\mathrm{~s}, 3 \mathrm{H}, \mathrm{SO}_{2} \mathrm{CH}_{3}\right), 3.46\left(\mathrm{t}, 1 \mathrm{H}, J_{3,4}=1.65\right.$ $\left.\mathrm{Hz}, \quad J_{4,5}=1.98 \mathrm{~Hz}, \mathrm{H}-4\right), 3.76(\mathrm{dd}, 1 \mathrm{H}$, $\left.J_{5,6}=5.94 \mathrm{~Hz}, J_{6,6}, 7.26 \mathrm{~Hz}, \mathrm{H}-6\right), 4.24(\mathrm{q}, 1 \mathrm{H}$, $\left.J_{2,3}=5.61 \mathrm{~Hz}, \mathrm{H}-3\right), 4.26\left(\mathrm{dd}, 1 \mathrm{H}, J_{5,6}=0.99\right.$ $\mathrm{Hz}, \mathrm{H}-6), 4.46$ (d, $1 \mathrm{H}, J=12.5 \mathrm{~Hz},-\mathrm{CH}_{2} \mathrm{Ph}$ ), $4.49\left(\mathrm{~d}, 1 \mathrm{H}, J=12.5 \mathrm{~Hz},-\mathrm{CH}_{2} \mathrm{Ph}\right), 4.50(\mathrm{~m}$, $1 \mathrm{H}, \mathrm{H}-5), 4.52\left(\mathrm{~d}, 1 \mathrm{H}, J=12.1 \mathrm{~Hz},-\mathrm{CH}_{2} \mathrm{Ph}\right.$ ), $4.71\left(\mathrm{~d}, 1 \mathrm{H}, J=12.1 \mathrm{~Hz},-\mathrm{CH}_{2} \mathrm{Ph}\right), 4.78(\mathrm{q}$, $1 \mathrm{H}, \mathrm{H}-2), 5.53(\mathrm{~d}, 1 \mathrm{H}, \mathrm{H}-1), 7.35(\mathrm{~s}, 10 \mathrm{H}$, $\mathrm{Ph}), v 1350 \mathrm{~cm}^{-1}\left(-\mathrm{OSO}_{2}-\right)$.

\section{1,6-Anhydro-2-O-benzoyl-3,4-di-O-benzyl- $\beta$ - D-mannopyranose (6)}

Benzoyl chloride $(2.06 \mathrm{ml}, 17.5 \mathrm{mmol})$ in pyridine $(2 \mathrm{ml})$ was dropped into a pyridine solution of 1,6 -anhydro-3,4-di- $O$-benzyl- $\beta$-Dmannopyranose $(4 ; 3.0 \mathrm{~g}, 8.77 \mathrm{mmol}$, pyridine: $5 \mathrm{ml}$ ) at room temperature. The residue was stirred at room temperature for $24 \mathrm{~h}$, poured into ice water, and extracted by chloroform which was washed by water, dried by sodium sulfate, evaporated, and five times chlomatographed on silicagel (dichloromethane as a eluent). 6 was obtained as a clear syrup. $(3.22 \mathrm{~g}$, $82.2 \%),[\alpha]_{\mathrm{D}}^{19}=-6.75^{\circ}, \delta_{\mathrm{H}}: 3.51(\mathrm{~s}, 1 \mathrm{H}, \mathrm{H}-4)$, $3.80\left(\mathrm{dd}, 1 \mathrm{H}, J_{6,6^{\prime}}=5.94 \mathrm{~Hz}, J_{5,6}=7.26 \mathrm{~Hz}\right.$, $\mathrm{H}-6), 4.16\left(\mathrm{q}, 1 \mathrm{H}, J_{2,3}=5.61 \mathrm{~Hz}, J_{3,4}=1.32 \mathrm{~Hz}\right.$, H-3), 4.29 (d, 1H, H-6'), 4.43, 4.55 (d, 2H, $\left.J=12.1 \mathrm{~Hz},-\mathrm{CH}_{2} \mathrm{Ph}\right), 4.45,4.58 \quad(\mathrm{~d}, 2 \mathrm{H}$, $\left.J=12.1 \mathrm{~Hz},-\mathrm{CH}_{2} \mathrm{Ph}\right), 4.59(\mathrm{~m}, 1 \mathrm{H}, \mathrm{H}-5), 5.10$ (q, 1H, H-2), 5.58 (d, 1H, H-1), 7.22 (s, 15H, $\mathrm{Ph})$.

\section{1,6-Anhydro-3,4-di-O-benzyl- $\beta$-D-arabino- hexopyranos-2-ulose (7)}

The activation of dimethyl sulfoxide was carried out according to Swern oxidation. ${ }^{13)}$ That is, to a cooled $\left(-60^{\circ} \mathrm{C}\right)$ solution of dimethyl sulfoxide $(0.916 \mathrm{ml}, 12.9 \mathrm{mmol})$ in dichloromethane $(4 \mathrm{ml})$ was dropped dichloromethane $(4 \mathrm{ml})$ containing oxalyl chloride $(0.564 \mathrm{ml}, 6.44 \mathrm{ml})$ under unhydrous condition. After the activation of dimethyl sulfoxide, a solution of $4(2.0 \mathrm{~g}, 0.584 \mathrm{mmol})$ in dichloro- methane $(10 \mathrm{ml})$ was injected into the activated dimethyl sulfoxide solution at $-70^{\circ} \mathrm{C}$, and the reaction mixture was stirred at $-15^{\circ} \mathrm{C}$ for $25 \mathrm{~min}$. A solution of triethylamine $(4.08 \mathrm{ml}$, $14.6 \mathrm{mmol})$ in dichloromethane $(5 \mathrm{ml})$ was added to the reaction mixture at $-30^{\circ} \mathrm{C}$, and stirred for 15 additional minute at $-15^{\circ} \mathrm{C}$. The reaction was quenched by water, and the residue was extracted by chloroform. The organic layer was washed by water, dried with sodium sulfate, and concentrated under reduced pressure. The residue was diluted by 1-chlorobutane, and recrystalized from 1chlorobutane solution fifth times. $(1.21 \mathrm{~g}$, $61.0 \%),[\alpha]_{\mathrm{D}}^{21}=-8.5^{\circ}, \delta_{\mathrm{H}}: 3.69(\mathrm{~d}, 1 \mathrm{H}$, $\left.J_{6,6^{\prime}}=6.60 \mathrm{~Hz}, \mathrm{H}-6^{\prime}\right), 3.86\left(\mathrm{q}, 1 \mathrm{H}, J_{5,6}=\right.$ $4.29 \mathrm{~Hz}, \mathrm{H}-6), 4.69$ (s, 3H, H-3 and $-\mathrm{CH}_{2} \mathrm{Ph}$ ), $4.88\left(\mathrm{dd}, 2 \mathrm{H}, J=12.2 \mathrm{~Hz},-\mathrm{CH}_{2} \mathrm{Ph}\right), 5.06(\mathrm{q}$, $\left.1 \mathrm{H}, J_{4,5}=5.28, \mathrm{H}-5\right), 5.45(\mathrm{~s}, 1 \mathrm{H}, \mathrm{H}-1), 6.86$ (d, 1H, H-4), $7.36(\mathrm{~s}, 10 \mathrm{H}, \mathrm{Ph}), v 1750 \mathrm{~cm}^{-1}$ $(\mathrm{C}=\mathrm{O})$.

\section{Polymerization}

Polymerizations of 1,6-anhydro- $\beta$-D-mannopyranose derivatives (5), (6), and (7) were conducted under various conditions for $48 \mathrm{~h}$ using phosphorous pentafluoride as the initiator under high vacuum. The polymerizations were terminated by methanol, and purified by reprecipitation using chloroform-methanol system five times. The products were freezedried from benzene solution. Average molecular weights were determined by gel-permeation chromatography using polystyrene as the standard. From the ${ }^{13} \mathrm{C}$ NMR spectra, stereoregularities were determined from integral numbers of the anomeric centers of the polymers. The results are summarized in Table I.

\section{RESULTS AND DISCUSSION}

\section{Synthesis of Anhydrosugar Monomers}

As shown in Scheme 1, all monomers were synthesized from 1,6-anhydro- $\beta$-D-mannopyranose (1) prepared by base-catalyzed cycliza- 
Table I. Polymerizations of 1,6-anhydro-3,4-di- $O$-benzyl-2- $O$-methanesulfonyl- $\beta$-D-mannopyranose (5), 1,6-anhydro2- $O$-benzoyl-3,4-di- $O$-benzyl- $\beta$-D-mannopyranose (6), and 1,6-anhydro-3,4-di- $O$-benzyl- $\beta$-D-arabino-hexopyranos-2ulose (7)

\begin{tabular}{|c|c|c|c|c|c|c|c|}
\hline No. & Monomer & $\begin{array}{c}\text { Initiator }^{\mathrm{a}} \\
\mathrm{mol} \%\end{array}$ & $\frac{\text { Temp }}{{ }^{\circ} \mathrm{C}}$ & $\frac{\text { Yield }}{\%}$ & $M_{n}{ }^{\mathrm{d}}$ & $\frac{[\alpha]_{D}^{20}}{\text { deg. }}$ & $\alpha$ Form $^{f}$ \\
\hline 1 & $5^{b}$ & 20 & 0 & 0 & & & \\
\hline 2 & & 20 & -40 & 0 & & & \\
\hline $3^{\mathrm{c}}$ & & 30 & -50 & 20.0 & $2.0 \times 10^{5}$ & n.d. & 100 \\
\hline 4 & & 10 & -50 & 0 & & & \\
\hline $5^{d}$ & & 100 & -50 & 16.8 & $2.4 \times 10^{5}$ & +34.7 & 100 \\
\hline 6 & & 20 & -60 & 15.6 & $1.6 \times 10^{5}$ & n.d. & 100 \\
\hline 7 & & 30 & -60 & 12.8 & $1.6 \times 10^{5}$ & n.d. & 100 \\
\hline 8 & & 5 & -78 & 0 & & & \\
\hline 9 & $6^{\mathrm{g}}$ & 20 & 0 & 14.8 & $2.2 \times 10^{3}$ & +1.84 & 73 \\
\hline 10 & & 10 & -20 & 20.2 & $2.3 \times 10^{3}$ & +2.12 & 69 \\
\hline $11^{\mathrm{h}}$ & & 30 & -40 & 48.2 & $2.7 \times 10^{3}$ & n.d. & 100 \\
\hline $12^{\mathrm{h}}$ & & 50 & -40 & 27.0 & $2.6 \times 10^{3}$ & n.d. & n.d. \\
\hline 13 & & 20 & -50 & 5.4 & $2.7 \times 10^{3}$ & +4.12 & 100 \\
\hline 14 & & 10 & -70 & 0 & & & \\
\hline 15 & $7^{i}$ & 20 & 0 & 0 & & & \\
\hline 16 & & 20 & -20 & 0 & & & \\
\hline 17 & & 20 & -50 & 0 & & & \\
\hline $18^{\mathrm{j}}$ & & 20 & -50 & 0 & & & \\
\hline
\end{tabular}

a Phosphorous pentafluoride was used as the initiator

b Monomer: $500 \mathrm{mg}$; solvent, $\mathrm{CH}_{2} \mathrm{Cl}_{2}: 3 \mathrm{ml}$.

c Monomer: $200 \mathrm{mg}$; solvent, $\mathrm{CH}_{2} \mathrm{Cl}_{2}: 0.6 \mathrm{ml}$.

d $\mathrm{A} \mathrm{CDCl}_{3}$ insoluble part was obtained.

e Determined by GPC polystyrene standard.

f Measured by ${ }^{13} \mathrm{C}$-NMR spectroscopy.

g Monomer: $500 \mathrm{mg}$; solvent, $\mathrm{CH}_{2} \mathrm{Cl}_{2}: 3 \mathrm{ml}$.

h Monomer: $500 \mathrm{mg}$; solvent, $\mathrm{CH}_{2} \mathrm{Cl}_{2}: 2 \mathrm{ml}$.

i Monomer: $200 \mathrm{mg}$; solvent, $\mathrm{CH}_{2} \mathrm{Cl}_{2}: 3 \mathrm{ml}$.

j Monomer: $200 \mathrm{mg}$; solvent, toluene: $3 \mathrm{ml}$.

tion according to Fraser-Reid. ${ }^{12}$ 1,6-Anhydro4- $O$-benzyl-2,3- $O$ - $(S)$-benzylidene- $\beta$-Dmannopyranose (3) was synthesized by benzylidenation of 1 followed by benzylation. The NOE spectrum of $\mathbf{3}$ showed that $\mathbf{3}$ was an endo isomer of two expected diastereomers, because of strong interactions between the proton on the asymmetric center of the benzylidene group and not H-6 protons but H-2 and H-3 protons (data not shown). The benzylidene group of $\mathbf{3}$ was reduced by lithium aluminum hydride and aluminum chloride ${ }^{14)}$ giving 1,6-anhydro-3,4-di- $O$-benzyl- $\beta$-Dmannopyranose (4), stereoselectively. For 2,3-
$O$ - $(S)$-benzylidene-pyranosides, the stereoselectivity of reduction, that is, the direction of cleavage of the dioxolane ring of the benzylidene group depends on the configuration of the acetal carbon atom, as reported by Lipták et al. ${ }^{15}$ They confirmed that the reduction of the exo isomer gave a derivative containing axial hydroxyl and equatorial $O$-benzyl groups, and from the endo isomer, a derivative with equatorial hydroxyl and axial $O$-benzyl groups was obtained. Our results show Liptak's rule to be applicable to 1,6-anhydro-hexopyranose.

Three new monomers were synthesized from 4. Methanesulfonylation and benzoylation of 
4 gave 1,6-anhydro-3,4-di- $O$-benzyl-2- $O$-methanesulfonyl- $\beta$-D-mannopyranose (5) and 1,6anhydro-2- $O$-benzoyl-3,4-di- $O$-benzyl- $\beta$-D-

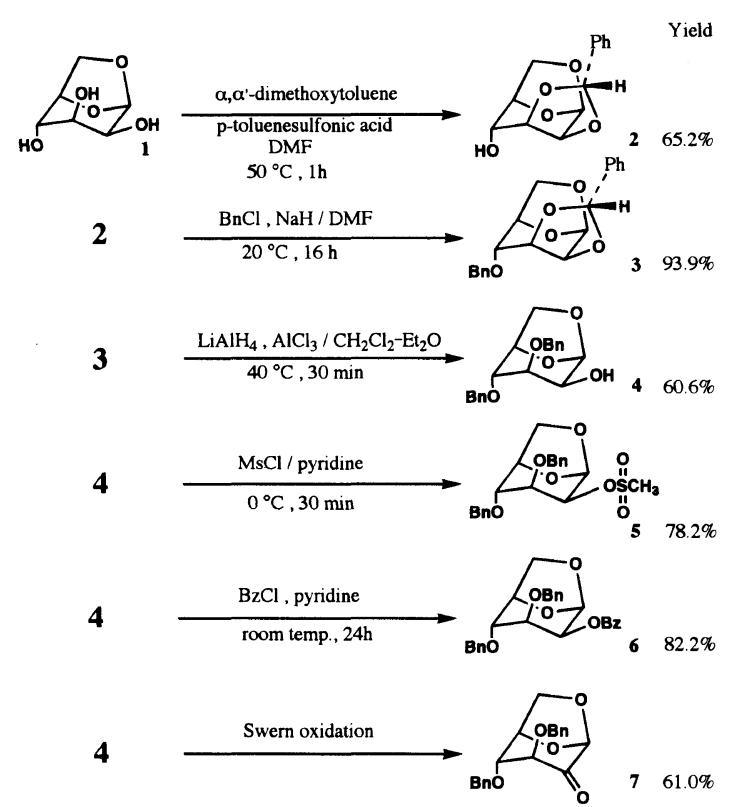

Scheme 1. Syntheses of 1,6-anhydro-3,4-di-O-benzyl-2$O$-methanesulfonyl- $\beta$-D-mannopyranose (5), 1,6-anhydro2- $O$-benzoyl-3,4-di- $O$-benzyl- $\beta$-D-mannopyranose (6) and 1,6 -anhydro-3,4-di- $O$-benzyl- $\beta$-D-arabino-hexsopyranos2-ulose (7).

mannopyranose (6), respectively. 1,6-Anhydro-3,4-di- $O$-benzyl- $\beta$-D-arabino-hexopyranos-2-ulose (7) was prepared by the Swern oxidation $^{13)}$ of 4 .

\section{Ring-Opening Polymerization}

1,6-Anhydrosugar monomers were polymerized by phosphorus pentafluoride as the initiator in methylene chloride at low temperature under high vacuum. As shown in Table 1, the polymerization of 5 proceeded at $-50^{\circ}$ and $-60^{\circ} \mathrm{C}$ using more than $20 \mathrm{~mol} \%$ of the initiator. The polymers were $3,4-\mathrm{di}-\mathrm{O}$ benzyl-2- $O$-methanesulfonyl- $(1 \rightarrow 6)-\alpha-\mathrm{D}-$ mannopyranans, whose stereoregularity was confirmed by specific rotations and ${ }^{13} \mathrm{C}-\mathrm{NMR}$ spectra of polymers (Figure 1), with high number average molecular weights of 1.6 $2.4 \times 10^{5}$. No polymer was obtained by the polymerization at $-40^{\circ} \mathrm{C}$ or above, most likely due to side reactions. Polymerization at an initiator concentration of $10 \mathrm{~mol} \%$ gave no polymer probably due to the coordination of the initiator to the methanesulfonyl group at C-2. Therefore, the polymerization of 5 requires relatively higher initiator concen-

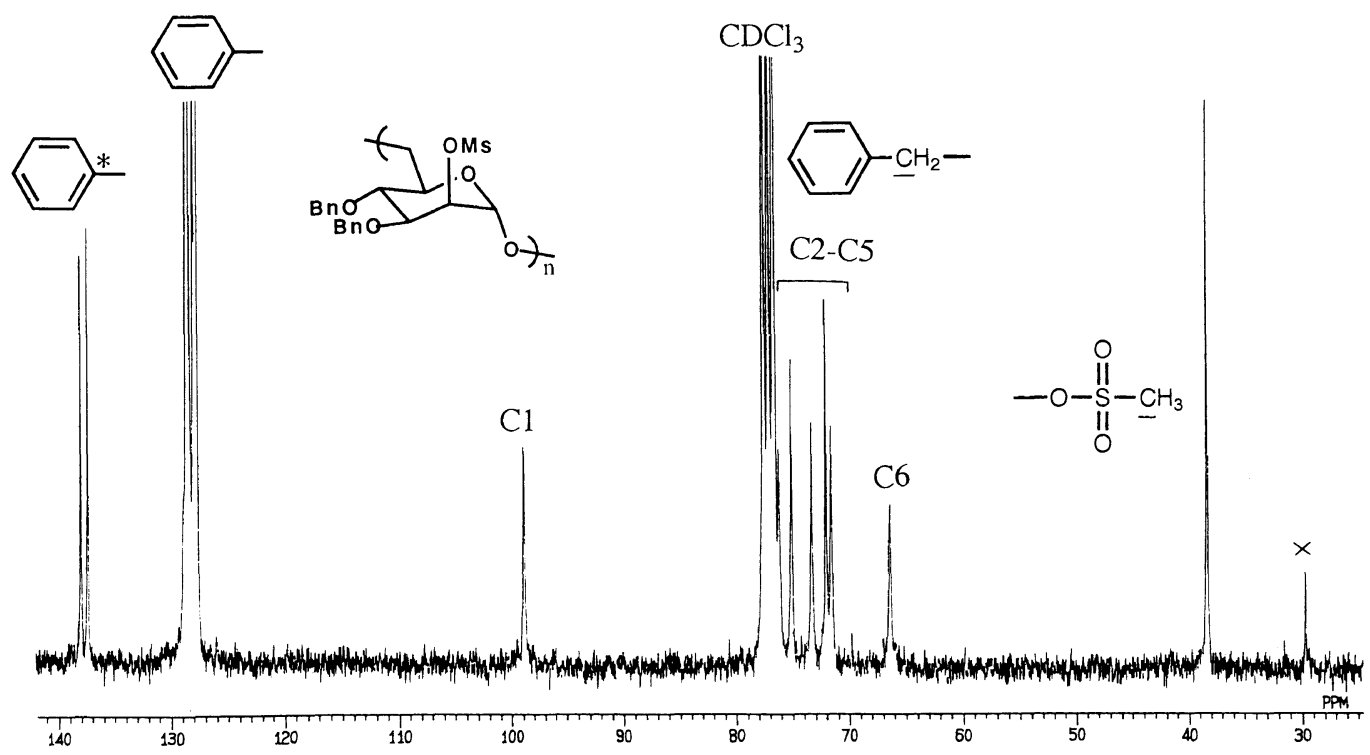

Figure 1. ${ }^{13} \mathrm{C}$ NMR spectrum of 3,4-di- $O$-benzyl-2- $O$-methanesulfonyl-(1 $\rightarrow 6$ )- $\alpha$-D-mannopyranan (No. 7 in Table I). 


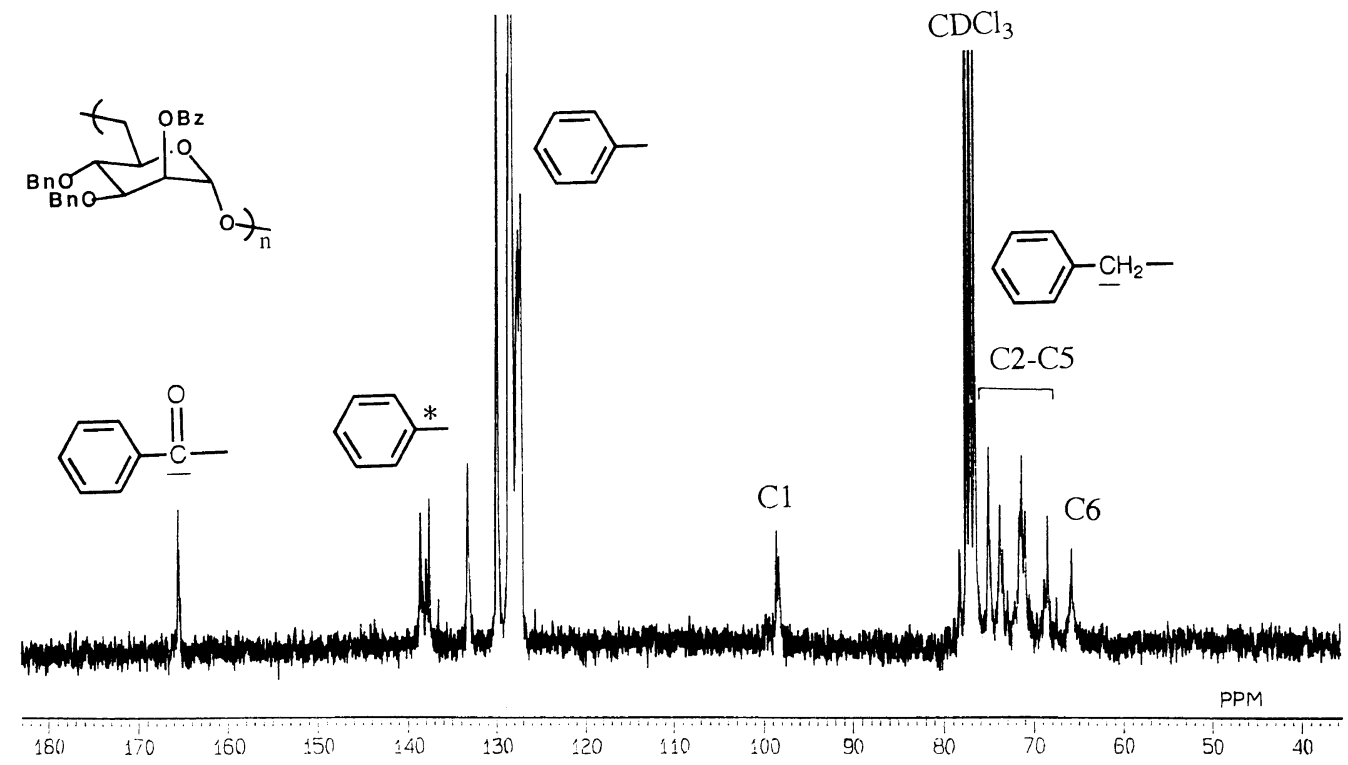

Figure 2. ${ }^{13} \mathrm{C}$ NMR spectrum of 2- $O$-benzoyl-3,4-di- $O$-benzyl-( $1 \rightarrow 6$ )- $\alpha$-D-mannopyranan (No. 13 in Table I).

tration and relatively lower tempercature. 3,4-di- $O$-benzyl-2- $O$-methanesulfonyl- $(1 \rightarrow 6)$ $\alpha$-D-mannopyranans may be an important precursors of 2-substituted $(1 \rightarrow 6)$ - $\alpha$-D-glucopyranan, because the $O$-methanesulfonyl group is a good leaving group in nucleophilic substitution reactions. 2- $O$-benzoyl derivative (6) was polymerized in the range of $-50^{\circ} \mathrm{C}$ to $0^{\circ} \mathrm{C}$ with more than $10 \mathrm{~mol} \%$ of the initiator. For all polymerization conditions, the number average molecular weight was low $(2.2-2.7 \times$ $10^{3}$ ), indicating that side reactions such as chain transfer reaction or interaction between cationic C-1 carbon and carbonyl group at C-2 may occur. 7 could not be polymerized under various conditions.

Differences of polymerizabilities of these monomers would be caused by the substituent at C-2 which affects the electron density of the propagating end and the nucleophilicity of 1,6-anhydro ring. Generally, in NMR spectroscopy, a downfield shift of proton occurs when bonded to the electron-withdrawing group, because of decrease in the electron density of the proton. Absorptions of $\mathrm{H}-1$ protons of 5 and $\mathbf{6}$ whose chemical shifts were 5.53 and $5.58 \mathrm{ppm}$, respectively, were appeared in a lower magnetic field than the peak of the $\mathrm{H}-1$ proton of tri- $O$-benzylated 1,6-anhydro-mannnopyranose $(5.45 \mathrm{ppm})$, indicating that the electron density of $\mathrm{H}-1$ protons of 5 and 6 was low. Therefore, the electron density of the anhydro-ring oxygens of 5 and 6 might be also lower than that of tri- $O$-benzylated 1,6-anhydro-mannnopyranose and the nucleopholicities of these anhydro-ring oxygen might decrease.

Since the methanesulfonyloxy group of $\mathbf{5}$ and benzoyloxy group of $\mathbf{6}$ are electron-withdrawing groups, the electron density of anhydro-ring in the monomer may decreases and the nucleophilic attack of the monomer may not occur easily. Therefore, the monomer reactivity of 1,6-anhydrosugar monomer having electron-withdrawing groups at C-2 was lower than that of perbenzylated 1,6-anhydrosugars.

In polymerizing 7 , the effect of functional group at C-2 was stronger. In addition to the electron-withdrawing effect as discussed above, 
oxa-carbenium ion possibly derived from 7 at the growing chain end should be stabilized by the formation of the conjugated system with a carbonyl group which has $\pi$ electrons. Moreover, there is the possibility of interactions between the carbonyl group and the initiator. That is to say, the extremely low polymerizability of 7 can be accounted for by the low reactivity of the monomer and cations.

Acknowledgements. We thank Kanagawa Academy of Science and Technology for making the NMR spectroscopy mesurements.

\section{REFERENCES}

1. P. J. Garegg, Acc. Chem. Res., 25, 575 (1992).

2. H. Kuyama, Y. Nakahara, T. Nukada, Y. Ito, Y. Nakahara, and T. Ogawa, Carbohydr. Res., 243, Cl (1993).

3. N. K. Kochetkov, Tetrahedron, 43, 2389 (1987).

4. Y. Ichikawa, Y-C. Lin, D. P. Dumas, G-J. Shen, E.
Garcia-Junceda, M. A. Williams, R. Bayer, C. Katcham, L. E. Walker, J. C. Paulson, and C-H. Wong, J. Am. Chem. Soc., 114, 9283 (1992).

5. S. Kobayashi, J. Shimada, K. Kashiwa, and S.-I. Shoda, Macromolecules, 25, 3237 (1992).

6. T. Uryu, J. Yamanouchi, T. Kato, S. Higuchi, and K. Matsuzaki, J. Am. Chem. Soc., 105, 6865(1983).

7. K. Hashimoto, K.-I. Mori, and M. Okada, Macromolecules, 25, 2592 (1992).

8. K. Kobayashi, H. Ichikawa, H. Sumitomo, and C. Schuerch, Macromorecules, 21, 543 (1988).

9. P. Konradsson, D. R. Mootoo, R. E. McDevitt, and B. Fraser-Reid, J. Chem. Soc., Chem. Commun., 270 (1990).

10. J. Zachoval and C. Schuerch, J. Am. Chem. Soc., 91, 1165-1169 (1969).

11. T. Uryu, K. Ito, K.-I. Kobayashi, and K. Matsuzaki, Makromol. Chem., 180, 1509 (1979).

12. M. Georges and B. Fraser-Reid, Carbohydr. Res., 127, 162 (1984).

13. Anthony J. Mancuso and Daniel Swern, Synthesis, 165 (1981).

14. A. Lipták, P. Fügedi, and P. Nánási, Carbohydr. Res., 65, 209 (1978).

15. A. Lipták, P. Fügedi, and P. Nánási, Carbohydr. Res., 51, C19 (1976). 